\title{
Azerbaijan Education System: Transition from Traditional to Modern Teaching and Learning Strategies. A Review of Literature
}

Musayeva, Aygun ; Jafarov, Elchin ${ }^{\text {; }}$ Badalov, Bakhtiyar ${ }^{\text {; }}$ Mammadova, Samira ${ }^{\text {d }}$ ${ }^{a}$ Social Work Department, Azerbaijan University, Azerbaijan; ${ }^{b}$ Education Department, Azerbaijan University, Azerbaijan; ${ }^{\mathrm{c}}$ International Relations Department, Azerbaijan University, Azerbaijan; ${ }^{\mathrm{d}}$ Department of Foreign Languages, Azerbaijan University, Azerbaijan

\begin{abstract}
Education plays important role in the society and in the everyday lives of plenty of people. Education influences people in different ways, and the significance of high quality education is indisputable. Particularly, innovation in education is a light that shows the humankind the right direction to surge. The advancement of the society directly dependent on the development of education and its quality. The fact is that, technological progress and innovative technologies application in education system bring new tools for struggling with complicated obligations in education systems. People get opportunities to express themselves, communicate and interact with other peoples in local, national and global context by using innovative technologies in education. The main purpose of study is to examine traditional and modern, innovative methods of teaching and learning, to explore the impact of these methods on educational environment and specifically discuss different teaching and learning methods regarding Azerbaijan education system.
\end{abstract}

Keywords: active teaching learning, teaching strategies, teaching techniques, benefits of active learning, active teaching in Azerbaijan. 


\section{Introduction}

The large-scale application of information technology to human life in modern age, the digitalization of everyday life in the context of globalization processes has given a boost to the development of society, and the discrepancy has been created between this speed and human development speed. Therefore, adapting the human development pace to the society's pace of development is one of the most urgent issues facing the modern era. In each society, this function is implemented by the education system. Thus, the education system should be built so that the individual can acquire knowledge in the field of narrow specialization selected in terms of the abundance of modern information, as well as the achievements of people separated into different groups can be coordinated and assembled. In fact, all the leading countries in the world are looking for this optimal model of education (Constituion of Azerbaijan Republic, 1995, Article. 42).

Studies show that education serves three different purposes depending on its level and trend: firstly, knowledge and experience to be used in this or other fields of action, to be applied in practice; secondly, to teach others knowledge and experience; thirdly, to raise the level of knowledge and experience, to gain new knowledge. The first one serves the application, the second - dissemination, and the third - increasing of knowledge and experience.

The educational system that aims at gaining success in each of these three areas, or the separately taken high school, should also put the proper organization of work on the easyto-master knowledge and skills acquisition. Because of this, world-wide learning and teaching methods should be analyzed, compared and the relevant method should be chosen according to the specificity of the subject. When making this choice, external experiments applied successfully should be studied, the applying possibilities of information technologies should be investigated, and new teaching and learning methods are to be applied, taking into account the needs of the globalized world. In our opinion, the succeed opportunity of higher education institutions in the teaching acted in the former Soviet Union is due to the above.

Over the past few years, active learning has attracted considerable attention. Often presented or perceived as a radical change from traditional learning, the subject often polarizes the ability. Active learning has attracted strong supporters among faculties who are looking for alternatives to traditional teaching methods, while the skeptical faculty sees active learning as another in a long series of educational fads. There are still questions about what active learning is and about its difference from traditional education teaching and learning methods. 
This study determines active learning and distinguishes between different types of active learning, most often discussed in the literature, and also analyzes their effectiveness compared to traditional teaching and learning methods.

At last, this study helps the Faculty of Engineering, summarizing some of the most relevant literature in the field of active learning (Cambridge International Examinations, 2015).

\section{What does mean active learning?}

Class room where students actively participate in the learning process and respond to learning opportunities by created knowledge and understanding is recognized as active learning. This contrasts with traditional chalk and talk model of learning which transmit knowledge from the teacher to the students.

Active learning is described with various terminologies in different research studies.

These terminologies include:

- Learner-centered, where students are actively engaged in learning, teachers play learning activist role rather than instructor.

- Problem-based/discovery-based research, where students examine and articulate different scientific issues, analyze related evidence, apply appropriate theories to collected evidence, come up with the conclusions and reflect on the results.

- Experiential learning, were students learn from direct experience.

Many authors define these terms somewhat differently, and such classifications of learning overlap with each other (Eison, 2010).

\section{Theoretical basis of active learning}

According to the theory of constructivism in active learning process students build or construct their own understanding. Within this process student create meaning, based on their prior knowledge gain deeper and more qualified level of understanding. Effective learning environment interaction between instructor and students provided by qualified training contribute to in-depth training (Li, M. P. \& Lam, B. H. 2005)

Social constructivism theory states that interaction with professor or with same age students generates learning.

Lev Vygotsky (1896-1934) as one prominent social constructivist has described the zone of proximal development (ZPD). This is an area where learning activities should be focused, 
lying between what the students can achieve on their own, and what the student can achieve with the help of the teacher's expert guidance. The objectives of the forest, providing guidance and support that challenge the student on the basis of their current abilities, and by providing rich feedback using the assessment for learning (see Separate Compendium), the teacher actively helps students to develop their deeper levels of understanding.

However active learning is consistent with other learning theories:

- According to the study conducted by Jean Jacques Rousseau (1712-1778) and other authors as John Dewey (1859-1952) and Maria Montessori (1870-1952) learning should be relevant and be in a meaningful context. It means that, human being better understand and learn when he/she practically sees the usefulness of knowledge and have an opportunity to connect it with the real world.

- Learning is development. Therefore, the study of experience for children should correspond to age, although the level of development and age do not always coincide (Eison, 2010).

\section{What are the advantages of active learning?}

Before discussing why it is important to use active learning and learning strategies, first, let's try to find an answer to the question "What is wrong with 50-minute lecture?".

In first glance, it seems that if lecture presentation is well designed and captures big amount of information, it would be time efficient way to cover course material by instructor.

Interactive lectures are presentations that provide students with multiple brief opportunities for structured engagement. In contrast to the traditional lecture, in interactive lectures instructor talks with periodic pauses for structured activities and for provision of longlasting student concentration, a short structured in-class activity is assigned. In contrast with interactive lectures in traditional lectures instructor talks \& students listen with minimal interruptions, students-to-student talk is discouraged. If instructor asks questions, students commonly respond by raising their hands. In most of cases, students are not provided with opportunities to correct misunderstandings during the lecture. Students listen to the instructor and take notes independently. All these factors, impact attendance rate of students in traditional lectures. In interactive lectures, students are encouraged to talk to each other and work with partners or in group. In the result of opportunities provided to students in interactive lectures, often high rates of attendance are reported.

According to various sources, promotion of deep and lasting student learning is cannot effectively achieved by listening to a classroom lecture. While lecturer transfers the information from his/her notes to students, transferred information is not passing from their minds and as a result, students are daydreaming, casually participate in the lecture, playing 
on laptops and listening music. The number of students who take notes in the lectures become less and less. If lecturer provides lecture by using Power Point Presentations student become careless, as they feel assured that slides are available and have easy access to them. At the same time, it is important to mention that, lecture method of teaching is considered relatively poor strategy for maintaining student attention. Thus, research findings suggest that student concentration during lectures begins to decline after 10-15 minutes (Michael Prince, 2004).

Different researches and national reports indicate that using active teaching learning strategies in the classroom is very important to achieve maximum student learning. In the result of large-scale analysis of studies was reported that, examining small group learning in SMET compared to traditional instruction methods high test scores and more positive student attitudes can be achieved.

Application of interactive teaching-learning strategies and creating active environment, result in change of instructor's, as well as student's roles in the class (Northern Ireland Curriculum, 2000).

Interactive techniques revive students from their passive mode and they become more attentive and engaged in class environment. Their activity and engagement are two main prerequisites for effective learning.

Examples of effective teaching and learning techniques are given below. However, it is important to mention that depending on teaching style and personality of the instructor his/her choice of interactive teaching-learning technique is influenced.

Think Break - instructor asks a kind of rhetorical question, and then lets students go into the details of the problem prior to explanation of the answer to the question for 20 seconds. Such method, even if discussion turns to be impossible, can motivate students to join the problem-solving process. When students take a note (while you are also writing answer), try to make sure that they are really involved in the problem-solving process (http://www.nsead.org/downloads/Effective_Questioning\&Talk.pdf).

Examining into notes - Instructor stops asking questions for a few minutes, so the students can get an opportunity to make comparisons among what they have written down through the given minutes, complete the gaps and prepare questions in concrete with the fellow students.

Skip the Chalk -Instructor brings a chalk or any kind of motivating item to students. Among the students the one who holds the chalk or that any item and answers the instructor's following question shall hand them over to any students he wishes. 
Table1. Roles of instructors and student in both active and passive teaching methods.

Instructor's roles

\begin{tabular}{l|l}
\hline \multicolumn{1}{c|}{ Passive } & \multicolumn{1}{c}{ Active } \\
\hline Teacher-centered classroom & Learner-centered classroom \\
Product-centered learning & Process-centered learning \\
Teacher as a 'transmitter of knowledge' & Teacher as an organizer of knowledge \\
Teacher as a 'doer' for children & Teachers as an 'enabler', facilitating \\
& pupils in their learning \\
Subject-specific focus & Holistic learning focus \\
\hline
\end{tabular}

Student's roles

\begin{tabular}{l|l}
\hline Passive & Active \\
\hline Being passive recipients of knowledge & Active and participatory learners \\
Focus on answering questions & Asking questions \\
Being 'spoon fed' & Taking responsibility for their own \\
& learning - reflective learners \\
Competing with one another & Collaborating in their learning \\
Wanting to have their own say & Actively listening to opinions of others \\
Learners of individual subjects & Connecting their learning \\
\hline
\end{tabular}

Tournament- Instructor divides the students into two or more groups and starts a competition to check their knowledge on the practical tests. So, it is better to allow the students to look through the topic with their group mates and complete the task to gain a point in the contest. 
After completing every single series of the contest, the instructor pauses for some minutes, so the students study the following task before scoring once more. The points the students gain are passed on to every next round of the contest. Students' stimulation and motivation for the contest will help them take a part and focus on the given materials.

One-minute papers - Students start writing answer to the given particular question during one minute, which is summarized as "write memorable things you have learned this lesson". This is one of the best methods to use at the end of each lesson (Thomas A. Angelo/K. Patricia Cross, 1993).

Gallery walk - Instructor provides stickers of different colors to students and assigns them to vote for any actions they have consented to with a greater number of class students. To complete the task, students must use small number of points for the topics written in advance and presented in the classroom on whiteboard or large printed pictures.

Think-Pair-Share -Instructor provides a few minutes for students, so students exchange their opinions with their team mates and make comparisons among their answers to the given question before discussing the responses with the classroom (ibid).

The task of written review for peers -Instructor asks the students to pass their project on to their peer team mate. The team mate looks through the project and notes 3 points he could focus on as it was his own project: the first paragraph of the essay underlines the high qualities of the project; the second part features the problems of the project whereas the third part gives a short conclusion the team mate has to pay attention to.

Jigsaw (Group experts) - Instructor asks each group to work on various subjects and separates them again into groups, assigns an experienced expert who will be teaching and guiding his peers for each subject. For the first day, it can be fruitful for the experts to teach the other distinct parts of the task.

Application for movies - The group members put forth a list of some films related to the subject or theme they have talked over in the classroom and make an effort to identify one or more (at least one) methods that directors of those films have properly realized and one or more methods to remove them.

TV-commercial -Students working in teams create a 20 or 30 -second TV ads or commercial regarding the subject they debated on in the classroom. Upon completion of the ads creation, the instructor asks them to present their advertising.

Blender -Students take notes about definitions on their own and then talk through the main idea for two or three minutes on paper. After the discussion, the students are separated into groups, two of which voice their ideas and combine the key aspects of each one. The third one also reads and then as previous one, integrates it with the previous two. Such process 
continues until every student of the group tried to unite the key elements of their ideas with the one coming before.

Simulation -To facilitate the Problem-Based Learning (PBL) student-centered teaching method, instructor exposes the students to a longtime simulation (for example, a model as a business).

Video-demonstrations -Using the advantages of modern technologies (for example, webcam), the students prepare a presentation connected with their subject and post it on Youtube or other websites.

Student videos -Instead of making PowerPoint slides, the lectures, discourses, projects and presentations of students can be presented by videos and be downloaded to get the fellow students to watch it.

Method of closed eyes -Instructor gives an assignment to the students to make their presentation with closed eyes to keep them from scrutinizing these presentations outside the classroom (here are included poems). The instructor should also remind the students of downloading the presentations on YouTube or other website that allows for class reviewing.

Video clips -Instructor shows short parts of well-known movies to draw attention to the point, opens a debate in which students pursue the fact the film is not correct, etc.

Colored boards -Under the guidance of the instructor, students generate a collection of three or more paper size cards. Such cards can be used to vote for the issues they discussed during class sessions by lifting up the relevant board or poster in the air. Probably the backside of each card will be white, which enable the students not to see the answers of fellow students.

Answer any three -Instructor writes 6 or more questions on the board and assigns the students to stand up (or stand beside the board) and answer any three of the given six or more questions written on the board.

Crossword -Before giving tests to students, instructor invents a crossword puzzle to help students view terms, meanings of words and general notions. Using some websites, such crossword puzzles can be automatically created (http://www.usf.edu/atle/documents/handout-interactive-techniques.pdf).

Considering the fact that students acquire knowledge by learning a language, studentcentered instructor should enable the students to get knowledge from conversations, reading and writing. To facilitate the understanding of the entire class, instructors should focus on using dialogues, debates and team works. Before generating a plan of teaching students, student-centered teachers will put their learning in a real-life context and try to know the 
key initial aspects of the understanding of students. Therefore, student-centered instructor pays attention to the process of differentiating and applies the following strategies appropriate to the assessment of learning:

- Practical questionnaire;

- Exchange of assessment factors;

- Giving feedback;

- Expert appraisal;

- Application of the assessment information in practice to adapt their teaching.

Students should understand that comprehension is more important than learning by heart. Through long-term comprehension the students will be able to memorize facts better rather than just studying them. They should realize the fact when approaching the lessons that, their future success in studies depends on their readiness to make mistakes, to take part in debates, to apprehend and acknowledge that they can sometimes make mistakes or learn from others' mistakes. So they have to actively "apprehend" ideas rather than just memorizing the facts.

To sum up, by generalizing the references on active learning we believe that, that this leads to an enhancement of the approaches of students and to development of their ability to think and write (Silberman, Mel., 1996, VanGundy, Arthur, 2005, Watkins, Ryan, 2005).

\section{Conclusion}

Since presently, the traditions of Soviet education are still in use as in most of CIS countries, the conformation of the education system to the Western standards is only of formal nature. Therefore, the key issue facing the countries of this region is not to be satisfied with formal reforms in education, but to make fundamental changes in accordance with the philosophical nature of education, real economic and social situation, new opportunities and requirements. We believe that, it is better to start the process of teaching and learning with a new point of view for all stages of education.

\section{References}

Constitution of the Republic of Azerbaijan 1995, Article 42, http://azerbaijan.az/portal/General/Constitution/constitution_01_e.html

Cambridge International Examinations (2015). Active learning. Retrieved from http://www.cambridgeinternational.org/images/271174-active-learning.pdf 
Eison, J. (2010). Using Active Learning Instructional Strategies to Create Excitement and Enhance Learning. Retrieved from

https://www.cte.cornell.edu/documents/presentations/Eisen-Handout.pdf

Li, M. P. \& Lam, B. H. Copyright 2005-2013 The Hong Kong Institute of Education All rights reserved. www.ied.edu.hk/aclass/

Michael Prince (2004).Does Active Learning Work? A Review of the Research. J. Engr. Education, 93(3), 223-231. Retrieved from http://www4.ncsu.edu/unity/lockers/users/f/felder/public/Papers/Prince_AL.pdf

Northern Ireland Curriculum (2000). Active learning and teaching methods for key stage. The Partnership Management Board. Retrieved from:

http://www.nicurriculum.org.uk/docs/key_stage_3/altm-ks3.pdf

Silberman, Mel. Active Learning: 101 Strategies to Teach Any Subject. Allyn and Bacon: Boston, 1996.

Thomas A. Angelo/K. Patricia Cross, Classroom Assessment Techniques. 2nd Edition. Jossey-Bass: San Francisco, 1993.

VanGundy, Arthur. 101 Activities for Teaching Creativity and Problem Solving. Pfeiffer: San Francisco, 2005.

Watkins, Ryan. 75 e-Learning Activities: Making Online Learning Interactive. San Francisco: Pfeiffer, 2005. 